\title{
A DYNAMIC MODEL OF VIRTUAL ORGANISATIONS: FORMATION AND DEVELOPMENT
}

\author{
Catherine Lackenby \\ University of Sunderland Business School, catherine.lackenby@sunderland.ac.uk \\ $U K$ \\ Hamid Seddighi \\ University of Sunderland Business School, hamid.seddighi@sunderland.ac.uk
}

$U K$

\begin{abstract}
Despite the rapid growth of virtual organisations in the global business environment, there is comparatively little theoretical work on their formation and operation. This paper proposes a model to explain their formation and operation. The model focuses on the concept of core competencies and identifies their development over time as the primary strategic objective of a firm within a virtual organisation. It is shown that pursuing this objective will inevitably result in "upstream" (Formation) and "downstream" (Operation) clusters within which virtual organisations are formed and operate. The model is dynamic, linking "upstream" and "downstream" clusters through a dynamic feedback mechanism.
\end{abstract}

\section{INTRODUCTION}

The last 30 years have witnessed a remarkable transformation of business environments in which manufacturing firms operate. Globalisation of business has increased competition to a level previously un-encountered (Banerjee, 2000). It is widely accepted that new organisation forms are emerging in response to such environmental trends as mass customisation, globalisation, rapid technological change, de-regulation, and shifting work force demographics (Miles et al, 1992). At the same time recent years have witnessed the emergence of a new paradigm, prompted by the realisation that by co-operating and collaborating along the supply chain, a significant competitive advantage may be secured.

The success of emerging structural forms, aimed at coping with the new competitive environment, such as the self-managed task team (Byrne, 1993), the network organisation (Powell, 1990), the international joint venture (Contractor and Lorange, 1988) and the virtual corporation (Davidow and Malone, 1992), rest largely on effective cooperation (Smith et al, 1995).

It is perhaps the virtual organisation concept that has truly captured the imagination of academics and practitioners alike, though to some extent it has been a victim of its own success. Increased popularity has led to a wealth of definitions, and a literature lacking rigour or systematic analysis in many areas. The ways in which these organisations are formed, or initiated, and then developed seems to be shrouded in some mystery. The impression often given is that a firm decides to take part in a virtual organisation one day, and is operating as such the next day. This impression may be misleading and requires clarification. 
The main purpose of this paper is to suggest a theoretical model of virtual organisation (VO) formation and development. To this end the paper will focus on the ways in which virtual organisations may be formed and developed over time, and in doing so clarify a number of points regarding the ability of firms to operate as virtual organisations. An operational definition will also be presented. Using the concept of core competencies a model is presented which suggest that focusing on core competencies will inevitably lead to the formation of two types of clusters of firms. The first "upstream" cluster provides an environment in which core competencies may be identified and refined ensuring that the firm is in fact capable of operating as a VO. The second "downstream" cluster enables those firms in the VO to operate as such, taking advantage of economies of scale through subcontracting, providing a rich source of firms to take part in another VO and so the process begins again.

\section{CHANGING MARKET REQUIREMENTS}

The era of competing primarily on the basis of quality, price or reliability is passing quickly for many manufacturers, only to be replaced by a competitive challenge based of flexibility, speed and responsiveness to the customer (Willis, 1998). Up to the 1980s the dominant paradigm for manufacturing firms was that of mass production, in which competitive strength lay in low cost production and economies of scale. Mass production involved the repeated division of a skilled task into many unskilled tasks in conjunction with capital investment, which ensured high levels of repeatability and thus high productivity (Booth, 1996). As global competition intensified mass production gave way to the concept of Lean Production" (Womack and Jones, 1990), in which emphasis was placed on the continual improvement of operations (Kaizen) the elimination of waste (Muda) and the avoidance of unwanted goods. Despite its ability to cope with smaller production runs and the resulting increase in variety, lean production is regarded by some as merely modifying the mass production paradigm rather than replacing it. Since lean production carries no spare inventory it cannot respond quickly to changes in demand.

Mass and lean production are typically associated with high levels of vertical integration, large scale operations and long production lines needed to take advantage of economies of scale. This traditional form of "full vertical integration" (Harrigan, 1984) which seeks to control the value chain through direct ownership has become increasingly unwieldy in today's business environment (Townsend et al, 1998). Whilst the inflexibility of these large vertically integrated firms is recognised in theory, in actuality the signs point to increasing size and concentration in a number if markets as evidenced by a large number of recent mergers and acquisitions (For example the UK Banking and Finance sector). Subsequently these firms are likely to be incapable of meeting the increasingly flexible and customised needs of its consumers, creating a distinct gap between what customers want and what firms are, in fact, capable of delivering. This gap is shown in diagram form in Figure 1 below 


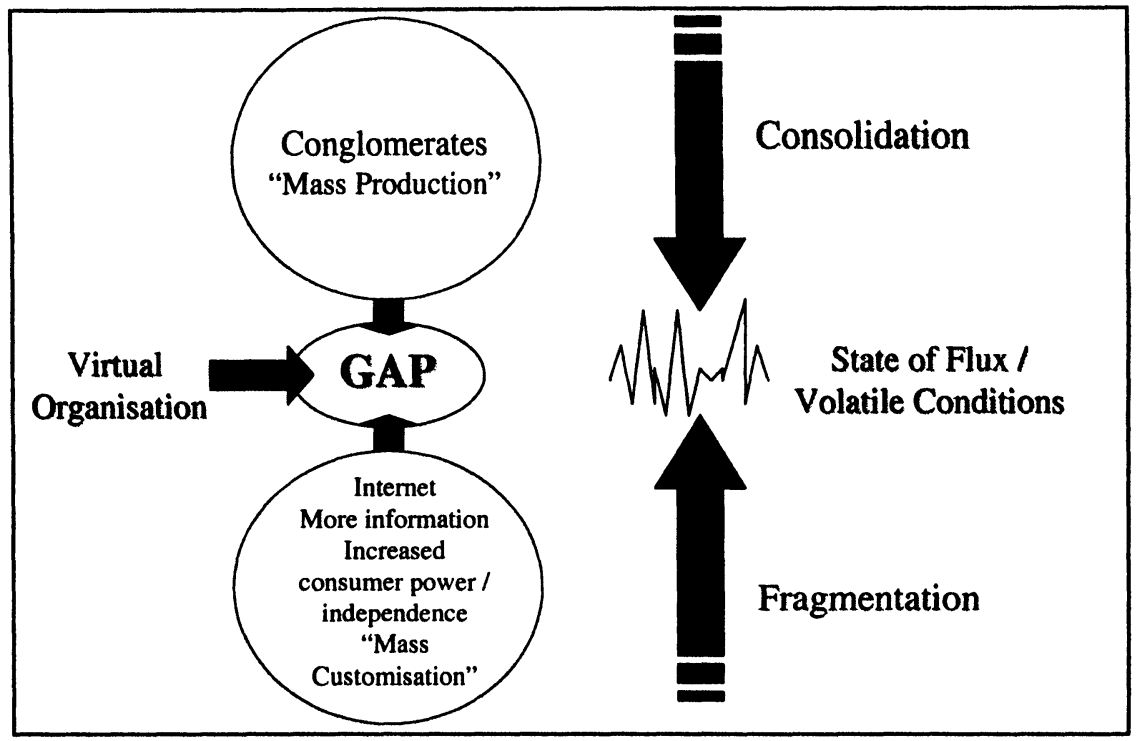

Figure 1 - Why Virtual Organisations are Needed

Not all firms or enterprises will be capable of filling such a gap. The firms that will thrive in today's hyper-competitive business environment are those able to anticipate market trends and respond quickly, to move quickly in and out of markets, products and even businesses (Stalk et al, 1990). Obviously this is impossible for traditional organisations, and the virtual organisation has been proposed as a means of filling this gap. For, as Tuma (1997) notes, the key idea of the virtual organisation is to concentrate on business strategies such as concentration on core competencies and maximum customer orientation. Most recently the virtual organisation has been cited as the means by which firms can successfully stay a pace of the market and provide what the customer actually wants. As mentioned earlier, the widespread attention given to the virtual organisation concept has resulted in a vast number of definitions, and consequently some confusion over what it actually is in practice. Nottingham (1999) however, suggests that although these models differ in detail and emphasis, they describe a similar phenomenon: a nebulous form of organisation whose existence is directly and immediately related to a specific objective. It is not the purpose of this paper to provide a review of the literature, ${ }^{1}$ but in order to proceed with the development of the theoretical model, a virtual organisation will be defined as follows;

A temporary alliance between a number of core competence based firms/individuals formed to take advantage of market opportunities.

This definition is similar to that presented by Walton and Whicker (1996) who define the virtual organisation as; "a series of co-operating "nodes" of core competence which form into a supply chain in order to address a specific opportunity in the market place".

\footnotetext{
' For a review of the virtual organisation literature see Seddighi et al, (2001)
} 
The definition that has been adopted in this paper however, emphasises the point that an individual with a core competence, such as particular market knowledge may take part in a virtual organisation. A single individual with a focused and defined core competence is as valuable a contributor to a virtual organisation as a firm with a focused and defined core competence. Size becomes irrelevant, contributors are measured only in terms of their core competence. Without a well-developed core competence, taking part in a $\mathrm{VO}$ is not a viable option for many firms or individuals. Figure 2 presents a model which emphasises the importance of focusing on core competencies in the development of virtual organisations. The stages of the model are described in the following section.

\section{A DYNAMIC MODEL OF THE FORMATION AND DEVELOPMENT OF VIRTUAL ORGANISATIONS}

Given the need to react to market opportunities, a firm/individual must clearly identify its core competence to fill the gap identified in Figure 1, in a time conscious manner. To this end a firm/individual seeks to ensure the following two conditions are met:

a) A well defined, focused core competence

b) A mode of delivery of the core competencies to the market which allows operations to take place rapidly and on a temporary basis.

The unit of analysis in our model is a firm operating in a globally competitive market. The firm as the starting point of analysis is in keeping with the Resource Based View (RBV) literature in strategic management (see Wernerfelt, 1984; Barney, 1991; Priem and Butler, 2001). The firm focuses on its "core competencies", is assumed to be able to identify and seeks to develop them over time to survive the global competition it faces.

\subsection{Stage One - Formation and Development Cluster}

The need to enhance and develop core competencies over time is critical for the firm if it is to succeed in the long term. Prahalad and Hamel (1990) importantly point out that it is those firms that successfully identify and cultivate their core competencies that can use them to obtain a sustainable competitive advantage. Core competencies should be developed over time, and continue to grow with repeated use (Thomas and Pollock, 1999).Given the focus of a firm on its core competencies, the firm's strategy is to enhance and develop them while achieving a competitive advantage. This strategy requires achieving two objectives;

1) Development of core competencies over time

2) Remaining competitive in terms of its costs and prices

The first objective is the key to the survival and indeed success of the firm. Although a firm's "core competencies" are perceived to be unique to a firm and are essentially best developed within the firm, they are enhanced and further developed through communities and sharing views among similar products, as firms do not 
consider firms with similar skills/core competencies as their rivals.

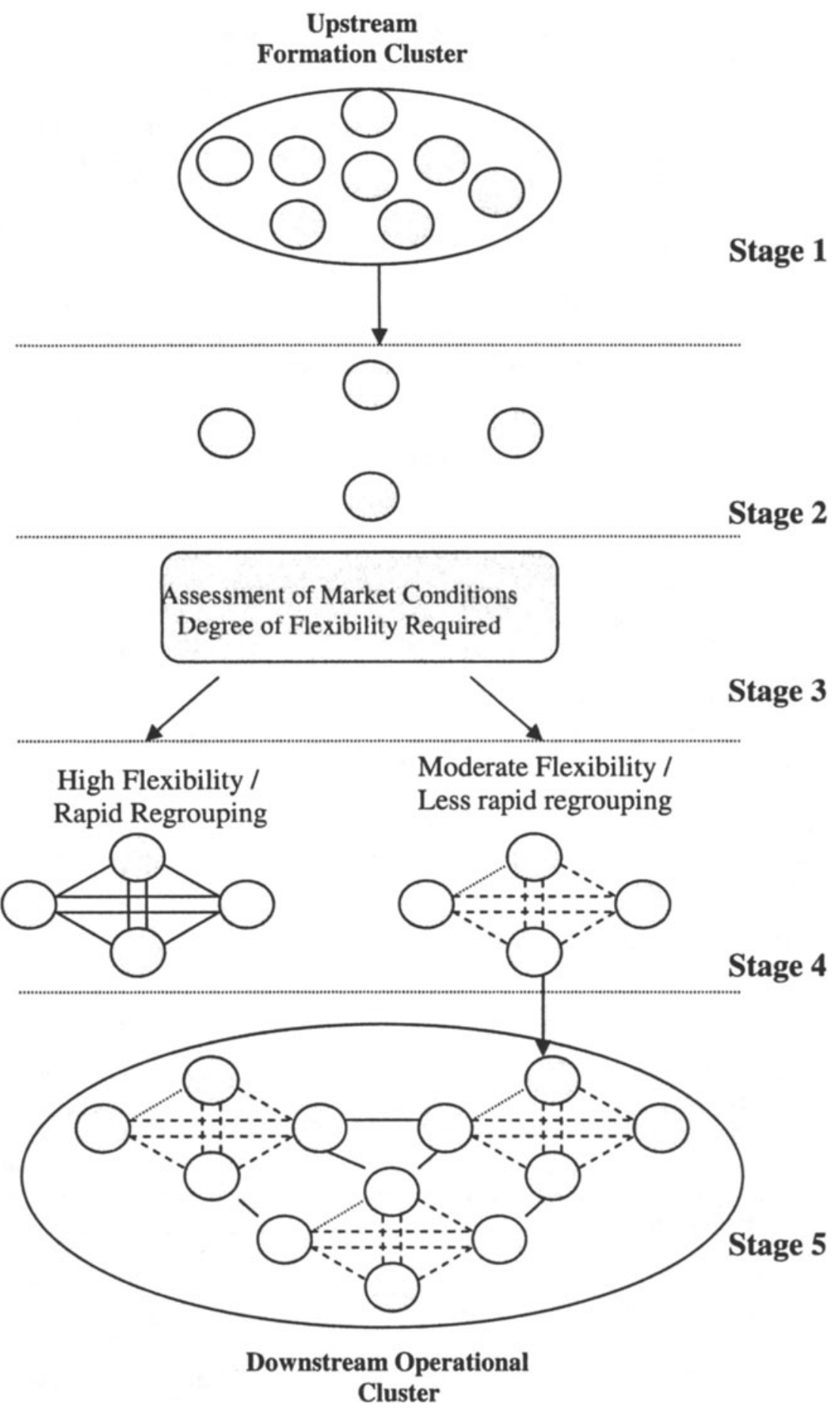

Figure 2 - A dynamic model of VO formation and development. 
This need for enhancing and developing core competencies through communications with non rival firms generates cognitive communities of firms who benefit from spill over effects of knowledge and skill development for their own specific operation rather than purely for achieving competitive advantage over their community members.

The existence and effects of knowledge spillovers as sources of innovative output and productivity growth have been an important research issue in the economics of technology (e.g. Griliches, 1991). A cluster provides a set of knowledge inputs that make for a technological infrastructure that supports innovative activity (Feldman and Audretsch, 1994). These inputs can come from competitors, firm in related industries, suppliers, customers and other entities carrying out research, such as universities. The argument is that innovative activity will tend to geographically concentrate close to agglomerations of this infrastructure, which is relatively immobile and place specific (Tassey, 1991) in order to benefit from spillovers.

\subsection{Stage Two - Leaving the Cluster.}

In order to remain competitive firms may choose to concentrate on core competencies and outsource everything else. Outsourcing offers several advantages, such as enabling existing staff to concentrate on core activities, focusing on achieving key strategic objectives, lowering or stabilising overhead costs, and thereby gaining cost advantage over the competition, providing flexibility in response to changing market conditions, and reducing investment in high technology (Kliem, 1999; Quinn, 1999). In its place is a vertically dis-integrated firm, concentrating on certain aspects of a business in which it perceives itself to have some advantage, or which are strategically critical to the firm. Firms found to be at stage Two of the model, are those firms who have developed and focussed their core competence within the cluster, but who feel they may earn higher profits by operating in a different context such as the virtual organisation. These higher profits are not available to them within the Formation Cluster, as it is essentially a traditional structure, with longer time horizons, incapable of earning the higher profits associated with quick response to a market opportunity.

\subsection{Stage Three - Assessing the Environment}

Once forms have left the Formation cluster with a well-defined, focussed core competency a number of decisions have to be made regarding the structure to be adopted. Whilst generally the time horizons within the virtual organisation are typically short, some opportunities may last slightly longer and have unique requirements which affect the structure of the organisation. The completion of this stage is fundamentally important in terms of its implications for the following stages.

\subsection{Stage Four - Determination of Structure Required}

The decisions made in Stage Three are reflected in the structure adopted at Stage Four. The model shows two possible "structures" for the organisation depending on the fleetingness of the business opportunity. This stage is important in the context of 
the management of the virtual organisation, as the choice of structure will influence the management processes, styles, and level of control necessary (See Seddighi et al, 2001).

\subsection{Stage Five - Operation Cluster}

To achieve global competitive advantage firms seek to develop their "core competencies" at a low cost of operation, involving raw material purchases, subcontracting of manufacturing activities etc. Each small firm on its own can not influence the cost of these activities, however if all firms in a cognitive community act together when some or all of these activities are to be carried out, each firm can enjoy a reduction in operational cost through economies of scale which are not available otherwise. The need to reduce transportation/delivery costs and other associated costs would lead to creation of clusters of firms in various geographical locations. A firm may take part in a virtual organisation, but it is likely that it will rely in some part on firms outside of itself i.e. raw material providers. More importantly, linkages may also develop between virtual organisations to provide a second down stream cluster. This is an operational cluster as opposed to the first cluster which aided in the development of single firms. In the upstream cluster benefits could be seen for locating close together, to trade information, know how etc. In this cluster it is recognised that certain advantages may be gained from colocating (i.e. reduced transportation costs), but being located near each other is less of an issue due to its "virtualness". The skills and experience from this stage are then fed back into the first cluster to assist other firms, and new members may also be drawn in.

\section{CONCLUSION}

This paper has drawn attention to the fact that in today's highly competitive environment there exists a substantial mismatch or "gap" between what "traditionally" organised firms are able to provide, and what more sophisticated and demanding customers are demanding. The Virtual Organisation is suggested as an organisational form capable of responding to customers needs in a highly competitive and unpredictable business environment. This paper, however, has focused on an area that has received comparatively little interest, that of the actual formation and development of the virtual organisations. A model was presented explaining the development and formation of virtual organisation in the context of concentrating on the development and focussing of core competencies through upstream "formation" clusters and downstream "operation" clusters. The model is currently being empirically tested with qualitative information.

\section{ACKNOWLEDGEMENTS}

The authors are grateful to ESF for funding this research project.

\section{REFERENCES}

1. Banerjee, S.K. "Developing manufacturing management strategies: Influence of technology and other issues.", International Journal of Production Economics, Vol. 64, 2000, pp.79-90. 
2. Baptista, R., Swann, P., "Do firms in clusters innovate more?", Research Policy, Vol. 27, 1998, pp.525-540.

3. Booth, R. (1996) Agile Manufacturing. Engineering Management Journal. 6:2, pp. 105-112.

4. Byrne, J., "The Horizontal Corporation", Business Week, Vol. 20, 1993, pp.76-81

5. Contractor, F.J. and Lorange, P., Co-operative Strategies in International Business. (Lexington, MA: Heath, 1988)

6. Cummings (Eds.) Research in Organizational Behaviour. 12, pp.295-336. (Greenwhich, CT: JAI Press, 1990)

7. Davidow, W.H., and Malone, M.S., The Virtual Corporation. (New York: Harper Collins, 1992)

8. Feldman, M., Audretsch, D., "Science based Diversity, Specialisation, Localised Competition and Innovation.", Paper presented at the $22^{\text {nd }}$ EARIE Conference, Sophia Antipolis, September.

9. Fill, C., Visser, E., "The outsourcing dilemma: A composite approach to the make or buy decision", Management Decision, Vol. 38, No. 1, 2000, pp. 43-50.

10. Griliches, Z., The Search for R\&D Spillovers. NBER Working Paper. No. 3768, 1991.

11. Harrigan, K.R. (1984) Formulating vertical integration strategies. Academy of Management Review. 9, pp 638-652.

12. Kliem, P., "Managing the risks of outsourcing agreements", Information Systems Management, Summer 1999, pp. 91-93.

13. McIvor, R., "A practical framework for understanding the outsourcing process", Supply Chain Management: An International Journal, Vol. 5 No. 1, 2000, pp.22-26.

14. Nottingham, A. (1999) The Virtual Organisation as a community built on trust. School of Information Management. Leeds Metropolitan University.

15. Porac, J.F., Thomas, H., "Cognitive Categorization and Subjective Rivalry Among Retailers in a Small City", Journal of Applied Psychology, Vol. 79, No. 1, 1994, pp. 54-66.

16. Prahalad, C., Hamel, G., "The core competence of the corporation", Harvard Business Review, Vol. 68, No.3, May-June 1990, pp. 79-91.

17. Priem, R.L., Butler, J.E. (2001) Is the resource based "view" a useful perspective for strategic management research? Academy of Management Review. Vol. 26 No. 1 pp. 22-40.

18. Quinn, J.B., "Strategic Outsourcing: leveraging knowledge capabilities", Sloan Management Review, Vol. 40, No. 4, 1999, pp. 9-22.

19. Quinn, J.B., The Intelligent Enterprise, New York, (NY: The Free Press, 1993)

20. Seddighi, H.R., Sandhu,m M., Bagher, M. (2001) A Model of the Virtual Organisation and Implications for Effective Management: An Empirical Analysis. B\&ESI Conference, 2001, Paris.

21. Smith, K.G., Carroll, S.J, Ashford, S.J., "Intra- and Interorganizational Co-operation: Towards a Research Agenda", Academy of Management Joumal, Vol. 38, No. 1, 1995, pp. 7-23.

22. Stalk, G., Evans, P., Shulman, L.E. (1992) Competing on capabilities: The New Rules of Corporate Strategy. Harvard Business Review. March-April, pp 57-69.

23. Tassey, G., "The functions of technology infrastructure in a competitive economy", Research Policy, Vol. 20, 1991, pp. 329-343.

24. Thomas, H, Pollock, T., "From I-O Economics' S-C-P Paradigm Through Strategic Groups to Competence-Based Competition: Reflections on the Puzzle of Competitive Strategy", British Journal of Management, Vol. 10, 1999, pp. 127-140.

25. Tuma, A. (1998) Configuration and coordination of virtual production networks. International Journal of Production Economics 56-57: 641-648.

26. Wernerfelt, B., "A Resource Based View of the Firm", Strategic Management Journal, Vol. 5, 1984, pp. 171-180

27. Willis, T.H. (1998) Operational competitive requirements for the twenty-first century. Industrial Management and Data Systems. 98:2, pp 83-86.

28. Walton, J. Whicker, L. (1996) Virtual Enterprise: myth and reality. Journal of Control, 22-25.

29. Womack, J.P., Jones, D.T., Roos, D. (1990) The Machine That Changed the World. Rawson Associates. 